\title{
Connect to Learn: Assemblage of Pedagogies in Higher Education in a Community of Practice
}

\author{
Elaine Fournier \\ Faculty of Education, Graduate Department \\ Western University \\ Mina Sedaghatjou \\ College of Liberal Arts and Science \\ Alfred University \\ Immaculate Namukasa \\ Faculty of Education \\ Western University
}

\section{Correspondence:}

Elaine Fournier

Faculty of Education, Graduate Department Western University

Email: efourni3 [at] uwo.ca

\begin{abstract}
In this paper, we report on the ways in which technology and scholarship of pedagogy emerge as interconnected within a technology-facilitated community of practice (CoP), for educators within various Faculties of Education in North American universities. The goal of the Community of Practice is to connect with and learn from one another, discussing, and reflecting on different types of pedagogical practices among members who teach in both graduate and teacher education programs in the onsite, blended, and online environments. We share analysis of interviews, and notes from CoP members' feedback; how the CoP members made sense of their diverse teaching and social learning landscapes as well as emergent joint meanings. The results of the study suggest that the assemblage of new ideas and pedagogies can be enhanced by a relational trust. A highlighted role of technology in enabling communication and collaboration among CoP members is also discussed through the lens of connectivism.
\end{abstract}

Keywords: technology-facilitated community of practice, pedagogy, connectivism, technology, scholarship 


\section{Introduction}

Professional learning opportunities in higher education have been impacted in an era of neoliberal management that highly values individualism (Apple, 2006; Rigas \& Kuchapski, 2016; Thorsen, 2010). To enhance the quality of teaching in higher education, faculty members sometimes participate and connect in professional development settings such as those happening in Communities of Practice (CoP). Members of a CoP share a passion for something they do and learn how to do it better as they interact regularly (Wenger-Trayner E. \& WengerTrayner B., 2014).

In university settings, learning is often considered an individual endeavor. However, Lave and Wenger (1991) proposed that learning is situated within a community and that it occurs when learners are deepening their participation in communities focused on a particular domain; this came to be known as a community of practice (Soto et al, 2019, p. 1).

Soto et al found that participation in a technology-facilitated lesson study built professional relationships and solidified their community of practice. Williams, Ritter, and Bullock (2012) found that the aim of a CoP was to strengthen the performance of experienced faculty members and to support new instructors' practice. A CoP is not always held in person because collaborators with common interests are not always located at the same physical location. Conole and Dyke (2004) envisioned that "the communication and collaborative abilities of technology [offer] the potential for [community] learning enriched by engagement" (p. 117) and "supporting the community rather than practice itself." (p. 295) That is to say, technology could be used as a medium not only to enhance instructional practices through the evolution of pedagogies but also to learn in a variety of ways including communities of practice and personal networks (Siemens, 2005).

Wegner, White, and Smith (2009) expanded the way that CoP develops within the emergence of new technologies and envisioned the advancements that virtual and online CoP will make possible. Later, in McDonald and Cater-Steel's (2017) edited volume on CoP, the role of synchronous and asynchronous communication in CoP was highlighted through the development of more productive CoP. They indicated that "a geographically dispersed but disciplinarily close-knit community can function as a supportive, non-hierarchical CoP based around mentorship, and generate significant social capital" (Schultz \& O'Brien, 2017, p. 502).

The CoP under study was designed to bring tenured full-time faculty, pre-tenure, and sessional staff together in a structured formal way to share and learn from one another related to issues of pedagogy. Originally designed as face-to-face meetings technology quickly became an integral aspect of the design of the CoP. The CoP was facilitated by an experienced academic. Meetings were held 4-5 times a year and an agenda was sent out prior to the meeting. Members were given the opportunity to suggest additional topics before the meetings. The purpose of this paper is to report on the process of connecting and learning in a technologyfacilitated CoP setting in a faculty of Education in North America.

\section{Assemblage of Ideas Through Connectivism}

Bandura's (1986) social cognitive theory describes the social diffusion of ideas, the acquisition of knowledge, and the adoption of new practices as well as how group functioning is the product of the coordinative dynamics of its members. Some of the factors he describes are the mix of 
knowledge and competencies of the group, how the group is structured, how its activities are coordinated, how well it is led, the strategies it adopts, and whether members interact with one another productively in mutually supportive or unproductively in undermining ways. To Bandura, the structure of social networks affects the social diffusion of ideas. People are enmeshed in networks of relationships that include kinship, friendships, occupational colleagues, and organizational members. They are linked not only directly by personal relationships but also by acquaintances which overlap different networks and landscapes of practices and as a result, a variety of people can become linked to one another indirectly by interconnected ties.

\section{Connectivist Learning Theory}

Bandura's social learning theory (1977) offers some insight into understanding what is happening within a particular CoP. It falls short however when trying to make sense of the complexity of numerous interactions between multiple CoP and how they intersect with one another. In an era of technology, Siemens (2005) theory of connectivism offered a construct to better understand the complexities of the networking that took place not just within the CoP under study but across the networks that were created as a result of this CoP as well. According to Siemen's theory of connectivism (2005), personal knowledge consists of a network, which feeds into organizations and institutions and in turn feeds back into the network, and then continues to provide learning to the individuals.

Siemens (2005) asserts that in the 21st century learning occurs in a variety of ways - such as communities of practice, personal networks, and through completion of work-related tasks. Siemens explains that the starting point of connectivism is the individual and that the capacity to form connections between sources of information and create useful information patterns is required to learn in our knowledge economy. In this paper, the individual refers to the members of the CoP that form the unit of analysis under study. Siemens' (2006) describes nine key principles that are integral to his theory:

- Learning and knowledge require diversity of opinions to present the whole and to permit the selection of best approaches;

- Learning is a network formation process of connecting specialized nodes of information sources;

- Knowledge rests in networks;

- Knowledge/learning may reside in non-human appliances, and learning is enabled/facilitated by technology;

- Capacity to know more is more critical than what is currently known;

- Learning and knowing are constant, ongoing processes (no end states or products);

- Ability to see connections and recognize patterns and make sense between fields, ideas, and concepts is a core skill for individuals today;

- Currency (accurate, up-to-date knowledge) is the intent of all connectivist learning activities; and

- Decision making is learning and choosing what to learn and the meaning of incoming information is seen through the lens of a shifting reality (Siemens, 2006). 
Several of Siemen's key principles emerged as salient features of the CoP discussed in this paper. Diversity of opinion, for example, was represented by the variety of pedagogies that the members enact, each bringing expertise to the group. The continuous learning that took place in the CoP and the very explicit decision making about what to learn more about also aligned with Siemens' principles. As well, the learning that took place in this CoP was facilitated by technology.

\section{Method of Inquiry}

In this exploratory case study, we sought to bring to light what outcomes emerged from engaging in the process of participating in the technology-facilitated CoP. The major unit of analysis is the learning community (Wenger, 1998) and its members. The qualitative evidence that we analyze here is derived from the CoP member's feedback and the analysis of the semistructured interviews with CoP members. The domain of our CoP included academics teaching in a faculty of education in a North American university. The faculty of education offers both online, onsite, and blended bachelors and graduate programs. The CoP was composed of 20 members over 2 years, where participants had experience teaching in one or all of these programs. CoP members were both part - and full - -time faculty members (tenure, tenure-track and sessional). Some members taught at more than one university. CoP members regularly met to develop, share, reflect on, and refine teaching ideas and experiences. The scholarship of this community was supported by an instructional design unit that supports teaching, a faculty unit offering technology support, and the collection of data for research purposes was approved by the ethics board of the university. During CoP meetings, the participants were provided with different materials both in in-person and technology technology-facilitated in order to express their ideas and members shared resources including research publications on pedagogy.

Polkinghorne (2005) asserted that because qualitative research expands our understanding of an experience there is a need to select "fertile examples of the experience for the study" ( $p$. 140). He encouraged the purposeful selection of participants and cautioned against leaving the selection to chance. He emphasized that the key should not be how much data were gathered or from how many but whether the data collected were sufficiently rich "to bring clarity to understanding an experience" (p. 140). It was with the intent to bring further clarity of understanding about the process of engaging in the technology-facilitated CoP that we set about to interview and to analyze follow-up reflection feedback and interview data of several members of the CoP.

Tashakkori and Teddlie (1998) stated that "the interview is a powerful method of data collection providing one-to-one interaction between the researcher and the individuals being studied" ( $p$. 102). The interview offers a variety of benefits: open-ended interviews result in copious information about issues and this may lead to the conceptualization of information in ways different from those initially anticipated. The interview was well suited for the questions being investigated in this study as it allowed for the exploration of multiple indices focused on the same construct, specifically, the ways in which CoP members made sense of their teaching and learning landscapes as well as emergent joint meanings. Therefore, we invited the CoP members to attend an hour of semi-structured interviews with the focus on their practiced pedagogies and how they are enacted; how they have learned about pedagogies from others, and how their participation in the CoP impact their pedagogies in practice (the full interview 
schedule is included in appendix A). The results and the analysis from both the CoP member reflection and the in-depth semi-structured interviews are described below.

\section{Analysis and Results}

Members of the CoP were invited to share their insights on the process of participating in the CoP and/or take part in an interview. Three members participated in the interview process and one member shared a written narrative.

As the research team, we chose to blend the data analysis and results into one section as this was well suited to our method of inquiry as described above. The data analysis and the ways in which we made sense of the narratives of the participants were interwoven into a holistic entity. The following is an excerpt from the reflective narrative shared by one member of the CoP:

As an educator who straddles both the academic (research) and practical (school principal) world, my actions are driven by my belief in the vital importance of bridging the divide between theory and practice. My desire to learn from and with academic colleagues in the CoP served two key functions; a desire to improve my practice through participation (self-efficacy) and a desire to contribute to the collective efficacy of the group. A number of factors facilitated my meaningful participation in the CoP. a) The CoP's openness to online participation afforded me access to participate in the group despite geographic distance; b) The leader's consistent communication via email gave me a sense of being in the loop; $c$ ) The various members of the CoP were genuinely interested in one another's professional successes and challenges. For example, a member's work in technology and mathematics held the potential to directly support our local school community of practice. In addition, my participation in the CoP supported my instructional leadership and most importantly the professional conversations that found their way to the [school] student desk!" (COPM0)

The COPMO's description of her learning within the CoP expands our understanding of the networked approach described by Siemens (2006) specifically the way in which the network formation connects specialized nodes (in this case the connection with another CoP member who had expertise in mathematics and technology pedagogy). The COPMO's pedagogy in her university teaching was enriched and at the same time, she was able to effectively utilize the new network that was created to support the learning of others within a completely different CoP.

Further explaining the importance of the members of the CoP being genuinely interested in one another's successes and challenges she offers the following explanation of the important role participating in the CoP held for her professional growth in relation to pedagogy and the role that relational trust played in this growth.

In my K-12 environment, professional learning opportunities often do not offer many avenues for critical reflection. Typically, we will engage in a book study and perhaps invite the author to speak once the book is complete. This is usually a smile and nod session where everyone (whether they have read the book or not) politely agrees with the author. No one feels safe enough to challenge what they have read so there isn't a

Open/Technology in Education, Society, and Scholarship Association Journal: 2021, Vol. 1(2) 1-19 
lot of genuine dialogue or new learning that emerges from these sessions. Within the CoP, I always felt challenged (I mean in a good way - cognitively challenged) to learn and grow. I always felt safe to share how I felt about a particular topic we might be discussing. The relationships that I formed allowed me to move my learning from within the CoP to outside of it and this further expanded my pedagogy. (COMPO)

The above narrative was noteworthy as it highlighted several of Siemen's principles of connectivist learning. For example, learning is a network formation connecting specialized nodes of information, and learning and knowledge require diversity of opinion. The important role these principles played for this CoP member also aligned with the narratives shared by the CoP members who participated in the interviews. Keywords such as safe, genuine, and relationship, highlighted the role of relational trust and surfaced as a critical element in both the written narrative as well as the interviews.

As we sought to gain a deeper understanding of the members' experiences we turned to the interview as a means to gather more data to further clarify our understanding of how the CoP members made sense of how the process of participating in a CoP impacted their pedagogy.

\section{Coding Procedure}

The participants' voices and experiences were heard through the rich narrative generated in the interview process. The data gathered were given specificity through a detailed process of coding and categorizing which followed the procedures made explicit by Glaser and Strauss (1967) and Strauss and Corbin (1990,1998). The coding allowed for the construction of meaning out of the narratives gathered. The first step in the analysis was to engage in an open coding process. During this phase, the transcribed data was broken down into units of meaning (concepts) and labeled (often using words that closely matched those of the participants). For example, the word talk was frequently used by the participants and this concept was labeled as verbal. The units of meaning typically ranged from several lines of text to a short paragraph. The coded units of meaning and the concepts were then grouped into categories (relational trust, enactment with students, technology, verbal, non-verbal,). These categories were assigned by the authors and emerged from the voice of the participants. For example, relational trust was mentioned in a variety of ways within and across participant interviews. This unit of meaning formed an important aspect of the key category collaboration. Together with the other key category, communication the voices of the participants were reassembled in an explanatory whole represented by the core category, assemblage of pedagogies. The core category incorporated the two key categories and articulated their relationship to one another.

Each transcribed interview was coded using the NVivo 12 software. The use of this particular software greatly facilitated the coding process described above. The software's various features corresponded to this process and made searching for concepts more manageable during the open coding process as it allowed for the storage and retrieval of multiple concepts. As well, the software allowed the researcher to create relationships between concepts which made the process described above a more manageable task.

The results of the data analysis from the semi-structured qualitative interviews are presented in two sections related to the key categories which emerged, namely, communication and collaboration. The model below depicts the elements that enrich and enable the Communities of 
Practice within and across the various networks that existed for the participants. Diverse forms of communication (verbal/nonverbal, technology-mediated) strengthened and expanded the CoP. Relational trust also emerged as an important concept which contributed to the success of the CoP.

\section{Figure1}

Categories and Key Categories in a Complex CoP Networking, Which Resulted in the Assemblage of Ideas and Pedagogies

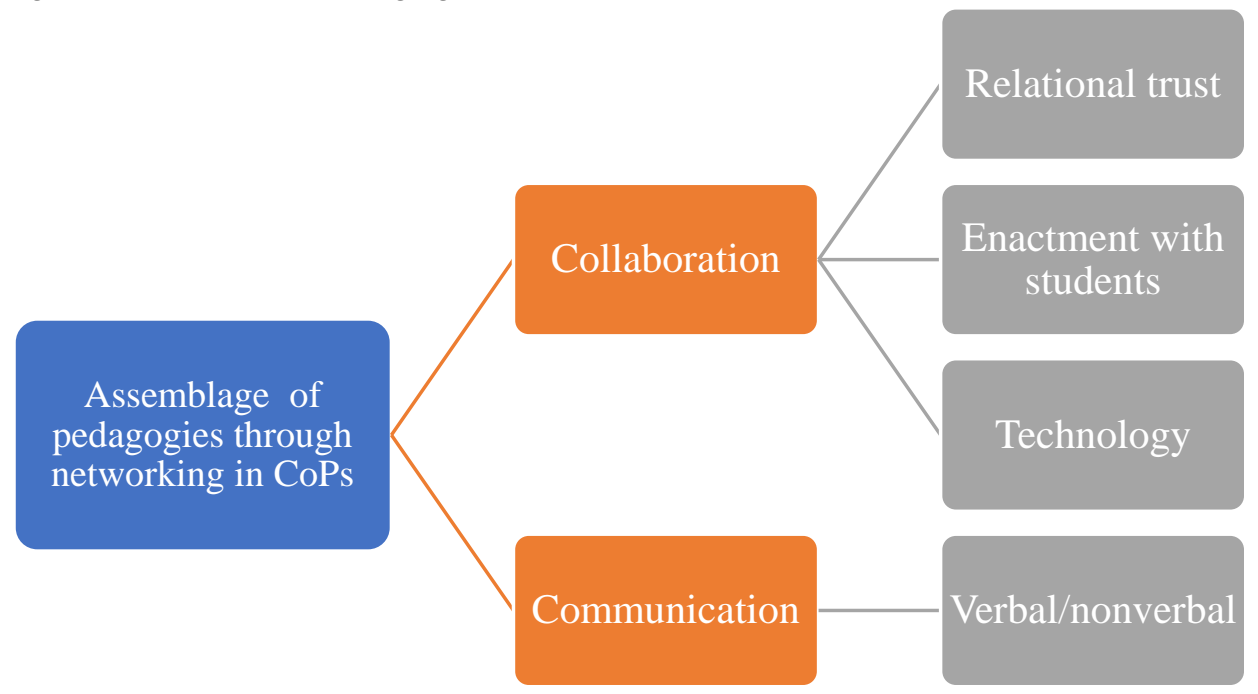

Throughout the results section, for ease and anonymity, $\operatorname{COPM}(1,2$, and 3$)$ refers to the members of the CoP who participated in the interview process and who are participants in the CoP that formed the basis of study.

\section{Communication}

The findings in this section emerged from the participants' practiced pedagogies and how they are enacted, as well as the way the participants spoke about the blending or interplay of the pedagogies. The findings suggest that those interviewed felt that communication was vitally important in how they enacted their pedagogy. It was evident from the ways in which the members described how they communicated their pedagogy that this was intertwined with the pedagogy itself. The vital role of the key category communication in teaching described in the interviews was derived from two concepts that often overlapped (verbal and non-verbal). For example, COPM2 described her pedagogy as primarily dialogical and she offered a rich narrative to impart the importance of verbal communication in the flow of knowledge between herself and her students:

My primary pedagogy is dialogue. I see education as the mediator's consideration of ideas, meaning the most effective way to mediate the students and myself in this is the capacity to dialogue. [COPM2]

She goes on to further describe her conceptual understanding of her pedagogy: 
Dialogue is a psychological tool and so it doesn't mean that we are just chatting. Dialogue isn't a conversation necessarily, dialogue is this cognitive activity that has infinite expression and so the dialogue could be non-verbal, it could be experiential. [COPM2]

For COPM3 communication in her teaching was primarily non-verbal. She describes her pedagogy as one rooted in project-based learning. She is animated in her description of the role that making and doing play when she communicates and orchestrates learning:

I talk a little bit but mostly it is getting a lot from them ... Having them make visuals, and create a lot of things.... they had to read to create something that was really highly visual and throughout the course, I encouraged them to create things ... that were useful for the community of teachers. [COPM3]

Whether they were communicating verbally or nonverbally what emerged from the participant's narratives was the important role that communication played in furthering the learning that had taken place and then sharing this learning with others.

\section{Collaboration}

The CoP members who participated in the interview were also asked to describe how they learned about pedagogies from others and in what ways their participation in the CoP impacted their pedagogies in practice. Collaboration emerged from the data as the other key coding category. This key category provides critical insight into the positive experiences as well as the challenges faced by the individual members and demonstrates the valuable role that the concepts of relational trust, enactment with students, and technology have played in mediating success and overcoming barriers.

\section{Relational Trust}

The authors have assigned the term relational trust to the meaning derived from the participants' own words. For purposes of this paper relational trust is defined as the interpersonal exchange that takes place in a group setting and is built on respect, personal regard, competence, and personal integrity (Bryk \& Schneider, 2003). The importance of relational trust was a salient feature of the narratives of the participants. For instance, COPM2 candidly shared how it was that she came to join the CoP under study.

I don't always feel my cohort members [in one of the university programs I participate in], I mean ... I ... trust your cohort community and so I don't have any peers in the higher ed. realm within my cohort and I was struggling a little bit ... The reason I found you guys was because I was looking for peers to talk about pedagogy. [COPM2]

She further reflected on the relationship within and between her various learning environments and on why she did not share the new learning that took place with her students with her book study peers. 
I didn't share that experience with my colleagues back in the community of practice... Maybe because... my peers were craving these tools [articulated in the book] and I just felt like I would be interrupting their desire to accumulate all of these pedagogical tools if I came back and talked about how I played with them.

COPM1 made a poignant declaration when she stated:

Participating in ongoing collaboration, dialogue, mutual trust, social networking, helping, and learning from colleagues, all of those things [mentioned in the interview question] are vital. [COPM1]

For other CoP members, the lack of relational trust that they encountered was much closer to the surface. COPM1 openly shared some of the challenges that she encountered while seeking out a CoP:

I talked to other teachers and, and because the other instructors because they've done it, and I actively sought them out for their wisdom and for their ideas ... And I just got the sense that people are like. yeah okay, but they didn't follow up with me, and I didn't get the vibe that they felt super comfortable with that. [COPM1]

COPM3 also shared how a lack of relational trust can inhibit meaningful collaboration with peers.

I wouldn't say so much [collaboration with peers]. With the one [... that I designed this course with, there was a lot of engagement and collaboration there, but with other people, not a lot of nurturing relationships and mutual trust.

It was evident from the thoughtful reflections of the participants that relational trust was an important factor in creating the right conditions for forming effective knowledge networks.

\section{Enactment with Students}

Another key theme that emerged was the way in which knowledge networks flowed back and forth between the participants and their students. The participants of this study shared the ways in which they made sense of their pedagogies via reciprocal knowledge sharing with their students. The authors labeled this process enactment with students. This theme expands our understanding of the way in which Siemen's (2005) theory of connectivism plays out in practice.

For instance, COPM2 described how she took the learning from a CoP (Book Study) and was able to create a network of new learning with her students.

... And so I came to class one day and shared with the students my experiences ... my hypothesis from the author ... so that we could use them to create a deeper understanding. [COPM2]

She also shares this powerful commentary about how and where the learning is situated for her: 
There is collaboration with my peers, ... I ...want to say that I'm learning there, But I'm not, I think because I disagree with [the author] we've chosen so it's interesting to read and think through why I disagree with him ... but l've learned the most so often in my practice with my students. [COPM2]

For COPM3 her approach to knowledge mobilization includes an expanded notion of networking in the form of "... create[ing] things that were useful for the [professional] community of teachers ... something that not only helps them learn but that will help other people learn."

She also shared her insights into how reflective practice with her students shapes the ways in which she enacts her pedagogy.

A lot of my ideas or a lot of new ideas ...come from my conversations... with my own students because this is a course on pedagogy ....and they have a lot of brilliant ideas, and in those discussions that have come up in class I have gotten a lot of new information, new perspectives, [and] new ideas. The conversations with my students have made me reflect more on pedagogy [and] made me learn more. [COPM3]

COPM2 further describes how the enactment of her project-based pedagogy is structured in such a way as to facilitate the learning of her students as they build on their knowledge base in the process of creating.

Students bring their own resources and experiences for meaning-making and it's our job as educators to tap into those resources. I strongly believe that the biggest learner in a room, in a classroom is the teacher. [COPM2]

As the networks with their students grew so too did the ideas and learning expand and grow for individual members of the CoP.

For each of the CoP members the ways in which an ongoing process of knowledge creation and the ways in which their pedagogies were enacted with their students allowed for the formation of new networks.

\section{The Role of Technology}

For the interview participants, technology played an important role in facilitating collaboration amongst peers within and across the CoP and it also enriched their enacted pedagogy with their students. The CoP under study utilized technology to enable participants from geographically diverse regions to gather on a regular basis in a synchronous manner. The participants were able to get to know one another and share their ideas, expertise, and wonderings in real-time and this helped to build trust amongst the participants. Utilizing the tools of the platform, online participants of the CoP were able to engage with their on-site peers in meaningful ways as they explored issues of pedagogy. For instance, COPM3 describes the various ways that her constructive interaction with her students is mediated by technology: 
I always try to apply it [constructive interaction] even in my field with online learning. ... And what that looks like is a lot of teamwork. It looks like a lot of product creation. ... A lot of collaboration. [COPM3]

She offers further insight into the role of technology when she describes with pride the types of knowledge artifacts that her students created which included videos, webpages, and other digital artifacts. Her students used technology to transmit learning within the group and across groups.

She shared how she then further expanded the network of learning via social media by asking permission from the students to share what she finds the best at helping in-service teachers in the broader community. I "tweet the ones that I think are the best." For this member technology also plays an important role in the types of CoP that she joins.

I would say that a lot of the ideas that I get to implement come from social networking and connectedness. ... I go on Twitter and I look [search] for specific words. ... I get a lot of ideas from there. [COPM3]

Another member, COPM2, shared how technology-enabled her to connect with another group of educators to further enrich their understanding of experiential learning.

I offered to lead, I'm not sure what we call it, so we're all at a distance so we come together through video conferencing for our staff meetings, and I'm leading ... the professional development portion of that now. And what I'm trying to do is choose experiential activities that we could enact in a, in a distance format. And I present those to my peers, so they have the opportunity to experience them from maybe from the students' perspective. And then ... we'll play with those ideas and those experiences, and then we'll step outside of them and talk about how we might use them in our practices as educators, and that's been pretty neat. [COPM2]

She also described the tensions that existed between her dialogical pedagogy and summative assessment and how technology afforded her the ability to reconcile some of those tensions with her students.

So how do I navigate that right now, I diversify my assessment and I narrate to them the tensions that I am experiencing [...] and I'm learning through technology to do that more dialogically ... [Technology] learning platforms allow me to annotate right within the document and that feels like dialogue. So, this is dialogue in feedback, and it feels good to me. [COPM2]

For the participants of the CoP in this study technology offered the opportunity to connect and learn on a regular basis. As relational trust developed from these connections collaboration and communication strengthened enabling opportunities for new networks of learning to emerge. 


\section{Discussion and Conclusion}

Each of the participants in this study was passionate about the pedagogies that they enact with their students and while the pedagogies themselves may differ, a unifying bond tied each of these diverse individuals together: their desire to connect and learn. Kop and Hill (2008) describe the usefulness of the theory of connectivism as a means to better understand that knowledge does not reside in one location but rather is a flow of information from multiple individuals seeking inquiry related to a common interest and providing feedback to one another (p.4). The rich data gleaned from the narrative of the CoP members revealed how this desire took shape within and across various CoPs. The study participants wanted to deepen and expand their pedagogy and this desire to connect and learn with others is represented in the model displayed in Figure 1. The nodes that Siemens (2005) describes offered a useful construct that enabled us to gain a deeper understanding of the participants' experiences as depicted in the model. For example, the insights that were shared by COPM2 as she described how she created a community of practice within and across nodes (her two communities of practice) and how this enabled her to enact her dialogical pedagogy and co-create new learning with her students. This learning originated in her university community of practice in the form of a book study but was transformed as it was enacted through co-created learning opportunities with her students.

The CoP members were asked to describe their experiences enacting and blending their pedagogies as well as their experiences with communities of practice and how their participation impacted their pedagogy. What emerged from their thoughtful discourse demonstrated the interconnection between the collaboration that took place between communities of practice and how this learning was shared with, co-created, and new learning emerged from the collaboration that they had with their students. When discussing the important role that connectivism plays in learning environments, Goldie (2016) asserts that knowledge and learning are not located in any given place but instead consist of networks of connections formed from experience and interactions between individuals, organizations, and technologies.

Specialized learning within specific communities of practice played a significant role for many of the participants. The member who offered written feedback shared the following insight:

As a result of my membership in the CoP, I had further opportunity to learn from another member about the use of technology to support the instructional dilemma" we were facing in my professional practice. This new learning led to a further opportunity to link the CoP member directly to the math lead at my school. Currently, we are implementing new approaches to support struggling learners as a direct result of my participation in the CoP. [COPM0]

Just like Williams, Ritter, and Bullock (2012), we found that technology-facilitated CoP's boost the performance of the faculty members through collaboration, communication, and learning with others and support the emergence of blended pedagogical practices. This linking of individuals and intersections of practices - in teacher education, in a faculty learning community, and with educators in K-12 - as evidenced by this member's experience with the CoP demonstrated the value of creating networks of specialized nodes of information sources as envisioned by Siemens. As the network expands, Siemens (2006) asserts that experts and 
amateurs become co-creators in knowledge. This key tenet of connectivism was apparent in the ways in which the various CoP members described the learning that takes place in their classrooms.

The study highlights the value of meaningful professional learning opportunities which overcome the constraints of individualism and foster greater collaboration in higher education. The findings suggest relational trust both within and across the various networks is needed for fostering collaboration and thereby creating more meaningful learning environments. We suggest that regardless of how the CoP is configured (structured, unstructured, formal, informal, in person, or online) what mattered the most to the participants was the knowledge creation within and across the networks that were created and that this ability to connect and learn was fostered and supported by strong relational trust. Technology played a pivotal role in supporting these networks both within and across communities. Sometimes this occurred by affording individuals the opportunity to connect where geography might otherwise have prevented them from doing so and sometimes it was by sharing the new knowledge creation that took place within a community of practice via social media.

Johnson (as cited in Siemens, 2006) argued that problems are becoming so complex that they cannot be contained in the mind of one individual. According to Johnson the challenge and opportunity for educators is to redesign the spaces for knowledge and learning to take place. The model in Figure 1 helps us to better conceptualize this ability to connect and learn through the interconnectedness of the key themes that emerged from the findings. Of the four themes, relational trust and technology stood out with regard to their ability to support the necessary conditions to foster effective collaboration and communication. Siemens (2006) states that connectivism allows individuals to learn and function in spite of the pace and flow. Instead of the individual having to evaluate and process every piece of information she/he creates a personal network of trusted nodes; people and content enhanced by technology (p.5). Technology is utilized in ways that further enhance the link between verbal and non-verbal communication and further shapes enactments of pedagogy with students in individual members' teaching. The findings from our study suggest that just such a redesigned space for knowledge and learning, in this case on pedagogy, can exist within a technology-mediated Community of Practice when relational trust is at the forefront making it possible for educators' abilities to connect and learn to truly flourish.

\section{Limitations and Suggestions for Further Investigations}

One of the limitations of the current study was that not all the members who were interviewed were able to attend all of the CoP meetings. A further limitation was that one of the members interviewed was new to the CoP. Furthermore, given the circumstances of the pandemic interviewees were not afforded choice as to the manner in which they preferred to participate in the interview.

A recommendation for further investigation would be to offer additional opportunities to share insights from additional members. Given that relational trust played such a key role for the participants in our study, opportunities for future research exist in examining more deeply how conditions and structures within a Community of Practice can develop and nurture this trust. Further examining the ways in which technology might be used within a CoP (pre-existing or newly formed) may offer additional insight into creating the optimal conditions to nurture and

Open/Technology in Education, Society, and Scholarship Association Journal: 2021, Vol. 1(2) 1-19 
sustain relational trust. As well, the results of our study indicated that the ways in which pedagogies were enacted with the students play a key role in creating and connecting new networks of learning for the faculty. Our study focused on this from the perspective of the higher education faculty however much could be learned from researching this same phenomenon from the perspective of their students.

\section{Author's Contributions}

E.F., M.S., and I.K.N, contributed to the design and implementation of the research, the analysis of the results, and the writing of the manuscript.

\section{Open Researcher and Contributor Identifier (ORCID)}

Elaine Fournier (iD https://orcid.org/0000-0002-1279-5504

Mina Sedaghatjou (D) https://orcid.org/0000-0003-4043-3604

Immaculate Kizito Namukasa (iD https://orcid.org/0000-0001-7231-0671

\section{Acknowledgements}

The authors of this study acknowledge the contributions of all CoP members who contributed to our CoP meetings and to this paper.

\section{Funding}

The activities of the group were in part supported by the Center for Teaching and Learning, at Western university.

\section{Ethics Statement}

Interview data collection was approved by Western University's NMREB.

\section{Conflict of Interest}

The authors do not declare any conflict of interest.

\section{Data Availability Statement}

Excerpts of original data for this article are only available upon reasonable request from the corresponding authors. The authors are unable to publicly publish the data nor to grant access to the full sets of the data ethically. This is because the study sample is a small population and participants are potentially recognizable, from anonymized data, by their employer or other employees. 


\section{References}

Apple, M.W. (2006). Understanding and interrupting neoliberalism and neoconservatism in education. Pedagogies: An International Journal, 1(1), 21-26.

https://doi.org/10.1207/s15544818ped0101 4

Bandura, A. (1986). Social foundations of thought and action: A social cognitive theory. Englewood Cliffs, NJ: Prentice Hall. http://www.worldcat.org/oclc/12080269

Bandura, A. (1997). Self-efficacy: The exercise of control. New York: W.H. Freeman and Company. http://www.worldcat.org/oclc/36074515

Bryk, A.S. \& Schneider, B. (2003). Trust in schools: A core resource for school reform. Educational Leadership, 60(6), 40-43. https://www.ascd.org/el/articles/trust-in-schools-acore-resource-for-school-reform

Conole, G., \& Dyke, M. (2004). What are the affordances of information and communication technologies? Research in Learning Technology, 12(2), 113-124. https://doi.org/10.1080/0968776042000216183

Goldie, J.G. (2016). Connectivism: A knowledge learning theory for the digital age? Medical Teacher, 38(10), 1064-1069. https://doi.org/10.3109/0142159X.2016.1173661

Glaser, B.G., \& Strauss, A.L. (1967). The discovery of grounded theory: Strategies for quantitative research. New York, NY: Aldine. ISBN: 9780202302607

Kop, R. \& Hill, A. (2008). Connectivism: Learning theory of the future or vestige of the past? International Review of Research in Open and Distance Learning, 9(3), 1-13. https://doi.org/10.19173/irrodl.v9i3.523

Polkinghorne, D.E. (2005). Language and meaning: Data collection in qualitative research. Journal of Counseling Psychology, 52, 137-145. https://doi.org/10.1037/0022$\underline{0167.52 .2 .137}$

McDonald J., \& Cater-Steel, A. (Eds), (2017), Implementing communities of practice in higher education: Dreamers and schemers. Springer, Singapore. https://doi.org/10.1007/978981-10-2866-3

Rigas, B., \& Kuchapski, R. (2016). "Strengthening” Ontario universities: A neoliberal reconstruction of higher education. Canadian Journal of Educational Administration and Policy, (180), 47-70. https://files.eric.ed.gov/fulltext/EJ1121387.pdf

Schultz, M. \& O’Brien, G. (2017), The Australian Chemistry Discipline Network: A supportive community of practice in a hard science. In $\mathrm{J}$ McDonald $\mathrm{J} \&$ A Cater-Steel (Eds.), Implementing communities of practice in higher education (pp. 501-530). Springer, Singapore. https://doi.org/10.1007/978-981-10-2866-3

Siemens, G. (2005). Connectivism: A learning theory for the digital age. International Journal of Instructional Technology and Distance Learning, 2(1). https://citeseerx.ist.psu.edu/viewdoc/download?doi=10.1.1.1083.5064\&rep=rep1\&type=p $\underline{\mathrm{df}}$

Siemens, G. (2006). Connectivism: Learning and knowledge today. Global Summit 2006: Technology Connected Futures. https://cupdf.com/document/george-siemens-globalsummit-2006-connectivism-learning-and-knowledge-today.html 
Soto, M., Gupta, D., Dick, L., \& Appelgate, M. (2019). Bridging distances: Professional development for higher education faculty through technology-facilitated lesson study. Journal of University Teaching and Learning Practice, 16(3), 1-19. https://files.eric.ed.gov/fulltext/EJ1224005.pdf

Strauss, A., \& Corbin, J. (1990). Basics of qualitative research: Grounded theory procedures and techniques. Newbury Park, CA: Sage.

Strauss, A., \& Corbin, J. (1998). Basics of qualitative research: Techniques and procedures for developing grounded theory. Thousand Oaks, CA: Sage. http://www.worldcat.org/oclc/39257153

Thorsen, D.E. (2010). The neoliberal challenge: What is neoliberalism? Contemporary Readings in Law and Social Justice, 2(2), 188-214. https://www.ceeol.com/search/articledetail?id=156221

Wenger-Trayner, E., \& Wenger-Trayner, B. (2015). Communities of practice: A brief introduction. http://wenger-trayner.com/wp-content/uploads/2015/04/07-Briefintroduction-to-communities-of-practice.pdf

Wenger-Trayner, E., \& Wenger-Trayner, B. (2014). Learning in landscapes of practice. Learning in landscapes of practice. Boundaries, identity, and knowledgeability in practice-based learning, 13-30. https://doi.org/10.4324/9781315777122

Wenger, E., White, N., \& Smith, J. (2010). Learning in communities. In U.D. Ehlers \& D. Schneckenberg (Eds.), Changing cultures in higher education (pp. 257-283). Springer Science \& Business Media, Berlin. https://www.springer.com/gp/book/9783642035814

Williams, J., Ritter, J., \& Bullock, S. (2012). Understanding the complexity of becoming a teacher educator: Experience, belonging, and practice within a professional learning community. Studying Teacher Education, 8(3), 245-260.

https://doi.org/10.1080/17425964.2012.719130 


\section{Appendix A}

\section{Individual Participant Interview Template}

\section{Recap on pedagogies used by an instructor in higher education}

At several meetings on the Conversations on Pedagogies COP members explored the pedagogies instructors use in their teaching in the faculty of education.

Members reflected on the pedagogies they use in practice: what these were and how they related to each other.

At this interview we are interested in hearing about your experiences and reflections of the pedagogies you use in your practice when teaching higher education course.

We are going to ask you to describe using words and images the pedagogies you use, to make connections to own learning of these pedagogies, reflect on the role of conversation on teaching and learning, and to share with us any hunches you may have on the impact of the pedagogies you use in practice.

Question

1. Describe the pedagogies you commonly use in your higher education teaching practices

Probes

- Which pedagogies do you practice?

How long you have been using these pedagogies? Have they evolved during that period of time? In yes, in what ways?

- Which pedagogies do you not practice? Why

$\circ$ Why these pedagogies? (repetitive)

- How are these enacted?

- Where did you learn about those pedagogies?

- How do you continue to support this learning and reflection on the pedagogies you use?

$\circ$ (Who are the scholars that you could name about these pedagogies?)

2. Making Images to represent the relations (interplay, blending, tensions) among pedagogies

\section{Context}

Here are some images that members made (Images are pasted in appendices at the end of the interview questions). Members used the images to articulate the relations (interplays, blending, tensions etc.) among the pedagogies they use in their practice. Let us speak more about the image you used or would/might use to show the blending or interplay of pedagogies.

For members who were at that meeting.

Here is an image in which you illustrated the ways in which different pedagogies are blended in practice:

$\underline{\text { Question }}$

$\circ$ What is illustrated in this image? 
- We would like you to speak more about this image (or another you might use to show the blending or interplay of pedagogies)

\section{Probes}

- What aspects of the image would you like to add to or take away from the image?

- Which aspects of the image would you like to highlight? And why?

- Which aspects would you like to illustrate with words or other media?

For members who were not at that meeting,

\section{Question}

- What images would/might you use? The image doesn't have to be one that we have shown. If you have a different image you would like to show or describe please do so.

\section{Probes}

- what images would you use to show relations among (or, articulate the interplay of the diverse) among the pedagogies you use in your teaching practices?

- What aspects of your image would you like to highlight? And why?

- Which aspects would you like to illustrate with words or other media?

\section{Expand and make connections to learning about pedagogies}

Question

3. In which of the following ways have you learned about pedagogies from others:

- Engagement?

- Collaboration?

- Reflective dialogue?

- Nurturing relationships and mutual trust?

- Social networking and connectedness?

- Exchanging information with colleagues inside the organization?

- Helping and learning from colleagues in order to develop professionally?

$\circ$ Professional dialogue?

Other? ....... What other activities do you engage in for the purpose of collectively constructing new meanings and improving the skills and knowledge that result in action?

\section{Probing a little further on the Role of conversations on teaching at the COP and elsewhere.}




\section{Questions}

4. Tell us about any formal or informal conversations on pedagogies that you participate(d) in

5. How do these conversations impact your pedagogies in practice?

6. How did your participation in the Pedagogies COP impact your pedagogies in practice?

7. In what ways did your participation in the CoP meetings affect your way of thinking about teaching and learning? Please give an example

8. Kindly recall a time when in the COP meetings or other informal conversations on pedagogies you learned something new, reflected on an idea/a pedagogy and you thought that you might want to try it with your students? Please give an example

9. What were some of the challenges/barriers that you encountered while participating in the COP

IV. Relation among the pedagogies you use and the students' learning, assessment and achievement

10. Kindly share with us your hunches (reflection, feedback) on the impact of the pedagogies you use in practice in relation to

- students' learning opportunities (and experiences) in your courses

- assessments you use in your courses

- feedback on the learning you give to the students

- learning outcomes (and achievements) of your students

\section{Possibility for future follow-up to this Interview:}

11. Thank you so much for your participation in this interview.

In line with the nature of the consent you gave on your consent form, on the section "Contact for Participation in Future Research Activities," we might contact you for a follow-up Focus group with other research participants.

Whether we need a focus group with other participants will depend on the analysis on the data we are currently collecting. 